\title{
Tyramide Signal-Amplified Immunofluorescence of MYCN and MYC in Human Tissue Specimens and Cell Line Cultures \\ Johanna M. Schafer ${ }^{1}$ and Jennifer A. Pietenpol ${ }^{1,2, *}$
}

\author{
${ }^{1}$ Department of Biochemistry, Vanderbilt University, Nashville, USA; ${ }^{2}$ Vanderbilt-Ingram Cancer Center, \\ Vanderbilt University Medical Center, Nashville, USA \\ *For correspondence: j.pietenpol@vumc.org
}

\begin{abstract}
[Abstract] MYC family members, MYC, MYCN, and MYCL, are oncogenic transcription factors that regulate the expression of genes involved in normal development, cell growth, proliferation, metabolism, and survival. While MYC is amplified and/or overexpressed across a variety of tissue types, MYCN is often overexpressed in tumors of the nervous system (neuroblastoma and medulloblastoma) or with neuroendocrine features (neuroendocrine prostate cancer). Given recent reports that MYCN expression is also deregulated in a variety of non-neuronal tissue types, we investigated whether MYCN was also deregulated in triple-negative breast cancer (TNBC). In contrast to previous individual immunofluorescence (IF) stains against higher expressing MYC family isoform protein, we developed an IF stain to simultaneously detect both MYCN- and MYC-expressing cells within the same tumor cell population. Our methodology allows for the detection of low level MYCN and MYC expression and can be multiplexed with additional protein probes. Herein, using tyramide signal amplification (TSA), we present two protocols for the IF detection of MYCN and MYC on formalin-fixed paraffin embedded (FFPE) tumor sections and in cell lines fixed in situ after growth as adherent cultures on chambered microscope slides.
\end{abstract}

Keywords: Cancer biology, Tyramide signal amplification, Immunofluorescence, Chamber slides, MYCN, MYC

[Background] Previous studies have demonstrated MYCN and MYC preferentially regulate the same set of core genes involved in metabolism and cell growth, and while the MYCN allele can functionally replace MYC in murine development (Malynn et al., 2000), MYCN and MYC have separate temporal regulation over organogenesis in early vertebrate development (Hurlin, 2013). MYCN expression is essential for initial establishment of stem and progenitor populations; over the course of organ system development, MYCN expression switches to low MYC expression to support stem and progenitor cell maintenance, and during cell lineage commitment and expansion, elevated MYC levels drive highly proliferative cells until they reach terminal differentiation (Hurlin, 2013).

A similar relationship has been observed in the development of TNBC metastases where MYCN expression is elevated in newly seeded metastatic lesions that expand and differentiate into highly proliferative MYC-expressing tumors (Lawson et al., 2015). Given the near ubiquitous nature of MYC deregulation across tumor tissue types, MYC is the most studied MYC family member. However, due to a correlation between deregulated MYCN expression and a poor prognosis (Beltran, 2014), MYCN has been increasingly studied in both neuronal and non-neuronal cancers, including acute myeloid leukemia 
(Kawagoe et al., 2007), small-cell lung cancer (Funa et al., 1987), ovarian cancer (Baratta et al., 2015), and now TNBC (Schafer et al., 2020). Therefore, we began to explore the relationship between MYCN and MYC by developing an IF stain that could simultaneously detect both isoforms within the same tumor tissue section. Established protocols that involve the IF detection of MYCN or MYC have been separate stains that primarily recognizes each isoform at highly amplified/overexpressed levels. Given that TNBC and other non-neuronal tissue types exhibit aberrant low-level MYCN expression, we developed a method to detect lower expression of MYCN and MYC using TSA. Further, we have two protocol versions of the method: application of the dual MYC family isoform (MYCN and MYC) TSA-IF to FFPE tumor sections, and a modified version of the stain for evaluation MYC family isoforms expression in cell line cultures fixed in situ after growth as adherent cultures on chambered microscope slides. We anticipate both MYCN and MYC are coexpressed in a variety of cancer tissue types and the advent of these IF methodologies will allow investigators to further characterize MYCN- versus MYCexpressing cells in tumor development and disease etiology.

\section{Materials and Reagents}

1. Microscopy slides (VWR, catalog number: 48311-703)

2. Coverslips (Fisherbrand, catalog number: 12-545K)

3. HistoPrep pen (Fischer Scientific, catalog number: 14-905-30)

4. PAP pen (Electron Microscopy Sciences, catalog number: 71310)

5. 10\% neutral buffered formalin (Thermo scientific, catalog number: 5701 ), store at room temperature

6. Xylene (Fisher Scientific, catalog number: X3P-1GAL), store at room temperature

7. Ethanol (Pharmco, catalog number: 111000200), store at room temperature

8. Citra plus antigen retrieval buffer (BioGenex, catalog number: HK080-9K), store at $4{ }^{\circ} \mathrm{C}$

9. Phosphate-buffered saline (Gelifesciences, HyClone, catalog number: SH30013.03), store at $4{ }^{\circ} \mathrm{C}$

10. Tween-20 (Acros Organics, catalog number: 23336-0010), store at room temperature

11. Triton X-100 (Millipore, OmniPur, catalog number: 9410 ), store at room temperature

12. $30 \%$ hydrogen peroxide $\left(\mathrm{H}_{2} \mathrm{O}_{2}\right)$ (Fisher Chemical, catalog number: $\left.\mathrm{H} 325-100\right)$, store at $4{ }^{\circ} \mathrm{C}$

13. Image-iT FX Signal Enhancer (Invitrogen, catalog number: I36933), store at $4{ }^{\circ} \mathrm{C}$

14. Goat serum (Gemini, catalog number: $100-109$ ), store at $-20^{\circ} \mathrm{C}$

15. DMSO (Sigma, catalog number: D2650-100ml), store at room temperature

16. FITC TSA reagent (PerkinElmer, catalog number: NEL741B001KT), store at $4{ }^{\circ} \mathrm{C}$

17. Cy3 TSA reagent (PerkinEImer, catalog number: NEL744B001KT), store at $4{ }^{\circ} \mathrm{C}$

18. Optional: Cy5 TSA reagent (PerkinElmer, catalog number: NEL745B001KT), store at $4{ }^{\circ} \mathrm{C}$

19. DAPI (Sigma-Aldrich, catalog number: D9542), store at $-20^{\circ} \mathrm{C}$, or Hoechst (Invitrogen, catalog number: $\mathrm{H} 3570$ ), store at $4{ }^{\circ} \mathrm{C}$ 
20. SlowFade Gold Antifade Mountant (ThermoFisher Scientific, catalog number: S36937), store at room temperature

21. Nail polish (any kind or brand will suffice)

22. Antibodies

a. Anti-MYCN antibody (Cell Signaling, catalog number: $51705 \mathrm{~S}$ ), store at $-20{ }^{\circ} \mathrm{C}$

b. Anti-MYC antibody (Abcam, catalog number: ab32072), store at $-20^{\circ} \mathrm{C}$

c. Anti-rabbit HRP secondary (Thermo Fisher Scientific, catalog number: 31462 ), store at $4{ }^{\circ} \mathrm{C}$

23. Permeabilization buffer (see Recipes)

24. Blocking buffer (see Recipes)

25. Antibody diluent (see Recipes)

26. Wash buffer (see Recipes)

27. FITC signal amplification buffer (see Recipes)

28. Cy3 signal amplification buffer (see Recipes)

\section{Additional materials and reagents required for cell line TSA-IF:}

1. Eight-well chamber microscope slides (Corning, catalog number: 354108 )

2. Methanol (Millipore, catalog number: MX0485-7), store at room temperature

3. Antibodies

a. Anti-Histone $\mathrm{H} 3$ antibody (Abcam, catalog number: ab1791), store at $-20^{\circ} \mathrm{C}$

b. Cy5-conjugated anti-rabbit secondary antibody (Invitrogen, catalog number: A10523), store at $4{ }^{\circ} \mathrm{C}$

\section{Equipment}

1. Slide Warmer (e.g., Lab-Line Instruments, model: CPC-600N1)

2. Electric pressure cooker (e.g., Cuisinart, model: CPC-600N1)

3. Microscope slide moisture chamber (e.g., Ted Pella, catalog number: 21053)

4. Slide staining station (e.g., Tissue-Tek, catalog number: 4451)

\section{Procedure}

\section{Tissue sections}

A. Sample fixation and preparation

1. When harvesting tissue, quickly place specimen (with a maximum thickness of $3 \mathrm{~mm}$ ) directly into $10 \%$ neutral buffered formalin and incubate tissue for $24 \mathrm{~h}$ at room temperature.

Note: Invert the container and/or mix contents every $30 \mathrm{~min}$ for the first few $h$ to ensure even exposure and proper fixation.

2. Transfer specimens to $70 \%$ ethanol and take tissue to appropriate facility for FFPE sample preparation. 
Note: If unable to process samples immediately, place specimens at $4{ }^{\circ} \mathrm{C}$.

3. Use standard microtone sectioning procedures to section tissue and dry specimens on positively charged microscope slides overnight.

Note: This protocol has been optimized for staining 4 micron thick FFPE tissue sections. If tissues are not to be stained immediately, dip slides in paraffin and store at $4{ }^{\circ} \mathrm{C}$.

B. Antigen retrieval

1. Label slides as desired with HistoPrep pen.

2. Melt paraffin wax by placing slides on slide warmer at $60{ }^{\circ} \mathrm{C}$ for $60 \mathrm{~min}$.

3. Quickly transfer slides to vertical slide holder already submerged in xylene.

4. Incubate slides in xylene four times for 10 min each.

5. Rehydrate tissue with graded alcohol incubations:
a. $100 \%$ ethanol: two separate incubations for $1 \mathrm{~min}$ each
b. $90 \%$ ethanol: two separate incubations for 1 min each
c. $75 \%$ ethanol: two separate incubations for $1 \mathrm{~min}$ each
d. $50 \%$ ethanol: two separate incubations for $1 \mathrm{~min}$ each
e. $\mathrm{dH}_{2} \mathrm{O}$ : two separate incubations for 5 min each

6. Transfer slides into $1 \mathrm{x}$ citra plus antigen retrieval buffer.

7. Add $175 \mathrm{ml}$ of $\mathrm{dH}_{2} \mathrm{O}$ to the base of pressure cooker and set program to high pressure (or $125^{\circ} \mathrm{C}$ ) for $4 \mathrm{~min}$.

8. Allow slides to remain in pressure cooker for another $30 \mathrm{~min}$ for depressurization and cooling.

9. Remove slides from pressure cooker and allow slides to cool further at room temperature (RT) for $45 \mathrm{~min}$.

10. Wash slides with $1 x$ PBS twice for 5 min each.

C. Blocking steps (do not allow your tissue to dry out):

1. Inactivate endogenous peroxidases by incubating slides in $3 \% \mathrm{H}_{2} \mathrm{O}_{2}$ (1:10 dilution of $30 \% \mathrm{H}_{2} \mathrm{O}_{2}$ in $1 \mathrm{x}$ PBS) at $\mathrm{RT}$ for $10 \mathrm{~min}$.

2. Wash slides with $1 \times$ PBS twice for 5 min each.

3. Permeabilize tissue with permeabilization buffer at RT for 20 min with gentle rocking.

4. Wash slides with $1 \times$ PBS twice for 5 min each.

5. Quickly vacuum off PBS around tissue, add PAP circle, place slide in microscope slide moisture chamber, and add PBS to tissue inside PAP circle until all slides are in place.

Note: Add 0.5-1 inch of water to bottom of microscope slide moisture chamber and keep chamber covered during incubations.

6. Aspirate PBS and incubate slides in Image-it Enhancer at RT for $30 \mathrm{~min}$.

7. Transfer slides to slide holder already submerged in blocking buffer and incubate at RT for $1 \mathrm{~h}$.

8. Wash slides with $1 \times$ PBS twice for 5 min each.

9. Return slides to microscope slide moisture chamber and add PBS to each slide until all slides 
have been transferred.

\section{MYC staining (TSA-IF round 1)}

1. Prepare the appropriate amount of antibody diluent with anti-MYC antibody at a 1:500 dilution.

2. Incubate slides with the diluted anti-MYC antibody at $4{ }^{\circ} \mathrm{C}$ overnight.

3. Transfer slides to slide holder already submerged in wash buffer and incubate $5 \mathrm{~min}$.

4. Wash slides further with $1 \times$ PBS three times for 5 min each.

5. Return slides to microscope slide moisture chamber and add PBS to each slide until all slides have been transferred.

6. Apply the anti-rabbit HRP secondary antibody at 1:1,000 in antibody diluent for $1 \mathrm{~h}$.

7. Transfer slides to slide holder already submerged in wash buffer and incubate $5 \mathrm{~min}$.

8. Wash slides further with $1 \times$ PBS three times for 5 min each.

9. Return slides to microscope slide moisture chamber and add PBS to each slide until all slides have been transferred.

10. Prepare the FITC SAB.

11. One slide at a time, aspirate PBS and apply the FITC SAB to tissue.

Note: This protocol has been optimized to apply the FITC SAB for 6 min. Incubation times may need to be optimized for a given experiment to ensure a robust signal and minimal background. The latter can be achieved by using positive and negative controls that differ in the amount of MYC transcript. When applying the stain across multiple slides, be extremely precise with timing. Start timer when FITC SAB is applied to first slide. Continue to replace PBS with FITC SAB and stop reaction at the exact designating time for each slide.

12. To stop reaction, transfer slide to wash buffer. Incubate $5 \mathrm{~min}$ in wash buffer after all slides have been transferred.

13. Wash slides with $1 \times$ PBS twice for 5 min each.

14. Wash slides with $\mathrm{dH}_{2} \mathrm{O}$ once for 5 min.

15. To prepare for the second antibody probe, perform the antigen retrieval Steps B6-B10. Note: At this point, FITC has been selectively conjugated to MYC-proximal tyrosine residues. Use of the pressure cooker at this step serves as the stripping method to remove the previously applied primary and secondary antibodies. Stated further in the Notes section, be sure to include appropriate controls to ensure the antibodies have been properly stripped.

16. Reblock tissue by performing Steps C1-C2 and C5-C9.

E. MYCN staining (TSA-IF round 2)

1. Prepare appropriate amount of antibody diluent with anti-MYCN antibody at a 1:500 dilution.

2. Incubate slides with the diluted anti-MYCN antibody at $4{ }^{\circ} \mathrm{C}$ overnight.

3. Transfer slides to slide holder already submerged in wash buffer and incubate $5 \mathrm{~min}$.

4. Wash slides further with $1 \times$ PBS three times for 5 min each.

5. Return slides to microscope slide moisture chamber and add PBS to each slide until all slides 
have been transferred.

6. Apply the anti-rabbit HRP secondary antibody at 1:1,000 in antibody diluent for $1 \mathrm{~h}$.

7. Transfer slides to slide holder already submerged in wash buffer and incubate $5 \mathrm{~min}$.

8. Wash slides further with $1 \times$ PBS three times for 5 min each.

9. Return slides to microscope slide moisture chamber and add PBS to each slide until all slides have been transferred.

10. Prepare the Cy3 SAB.

11. One slide at a time, aspirate PBS and apply the Cy3 SAB to tissue.

Note: This protocol has been optimized to apply the CY3 SAB for 8 min. Incubation times may need to be optimized for a given experiment to ensure a robust signal and minimal background. The latter can be achieved by using positive and negative controls that differ in the amount of MYCN transcript. When applying the stain across multiple slides, be extremely precise with timing. Start timer when CY3 SAB is applied to first slide. Continue to replace PBS with CY3 $S A B$ and stop reaction at the exact designating time for each slide.

12. To stop reaction, transfer slide to wash buffer. Incubate $5 \mathrm{~min}$ in wash buffer after all slides have been transferred.

13. Wash slides with $1 \times$ PBS twice for 5 min each.

14. Apply either DAPI at $1: 50,000$ or Hoechst at $1: 2,000$ at RT for $15 \mathrm{~min}$. Note: Increase length of incubation if a shorter exposure time at the microscope is needed.

15. Wash slides with $1 \times$ PBS three times for 5 min each.

16. Seal tissue by applying 2-4 drops of SlowFade Gold Antifade Mountant, laying on cover slip, gently applying pressure to roll out bubbles and wicking off excess mounting medium.

17. Lay flat and allow slides to dry overnight at RT shielded from light.

Note: For longer term use, seal edges of coverslip with nail polish and store at $4{ }^{\circ} \mathrm{C}$.

\section{Chamber slides}

A. Slide preparation

1. Optimize seeding density for chamber slides so cells are near confluent at time of fixation.

Note: This protocol has been optimized for 8-well chamber slides and fixation 4-5 days after cell seeding.

2. Perform a quick wash with $1 \times$ PBS.

3. Incubate slides in $100 \%$ methanol for $10 \mathrm{~min}$.

4. Wash slides with $1 \times$ PBS twice for 5 min each.

Note: Depending on experimental design, chambers can be removed off of slides at this point or anytime here after. Remove chambers according to manufacturer's recommendations in the presence of PBS and do not let cells dry out.

B. Blocking and antibody incubations 
1. Perform blocking steps and antibody incubations as you would for FFPE tissue described in the previous section, Procedures C, D and Steps E1-E13.

2. Wash slides with $\mathrm{dH}_{2} \mathrm{O}$ once for 5 min.

3. To prepare for the third antibody probe, perform the antigen retrieval and reblocking steps as you would for FFPE tissue described in the previous section, Steps B6-B10, C1-C2, and C5-C9.

4. Apply the histone $\mathrm{H} 3$ antibody at $1: 100$ and incubate at $4{ }^{\circ} \mathrm{C}$ overnight.

Note: Application of the histone $\mathrm{H} 3$ antibody acts as the nuclear counterstain. After the antigen retrieval step(s), nuclear dyes such as DAPI and Hoechst will no longer completely localize to the nucleus.

5. Transfer slides to slide holder already submerged in wash buffer and incubate $5 \mathrm{~min}$.

6. Wash slides further with $1 \times$ PBS three times for 5 min each.

7. Return slides to microscope slide moisture chamber and add PBS to each slide until all slides have been transferred.

8. Apply the Cy5-conjugated anti-rabbit secondary antibody at 1:200 and incubate at RT for $1 \mathrm{~h}$.

9. Transfer slides to slide holder already submerged in wash buffer and incubate $5 \mathrm{~min}$.

10. Wash slides further with $1 \times$ PBS three times for 5 min each.

11. Seal tissue by applying 4-6 drops of SlowFade Gold Antifade Mountant, laying on cover slip, gently applying pressure to roll out bubbles and wicking off excess mounting medium.

12. Lay flat and allow slides to dry overnight at RT shielded from light.

13. Seal edges of coverslip with nail polish (apply at least three coats to ensure cells are fully sealed and the mountant does not leak) and store at $4{ }^{\circ} \mathrm{C}$.

\section{Data analysis}

1. FFPE tissue sections: manually take pictures or perform whole slide fluorescence imaging without overexposing each fluorophore. Composite FITC [excitation (494 nM), emission (517 $\mathrm{nM})$ ], Cy3 [excitation (550 nM), emission (570 nM)] and DAPI [excitation (358 nM), emission $(461 \mathrm{nM})]$ images as single channel and overlaid images (Figure 1).

2. Chamber slides: while cells primarily grow as a monolayer, we recommend whole slide Z-stack fluorescence imaging.

Any cell/tissue sections that dry out during the staining procedure will cause increased fluorescence intensity and background. Use MYCN and MYC positive and negative controls to dictate fluorophore exposure levels. Avoid capturing images near the edge of tissue. 
A
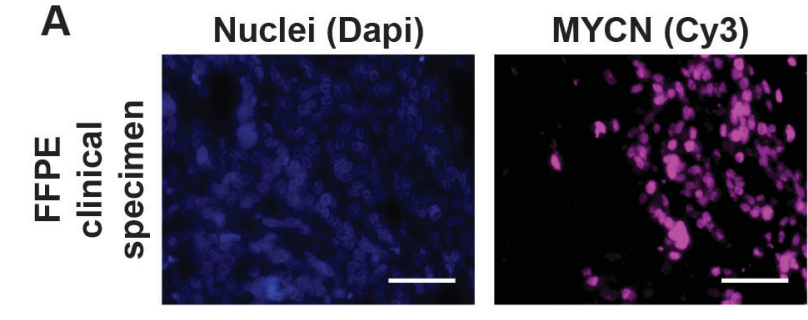

MYC (FITC)

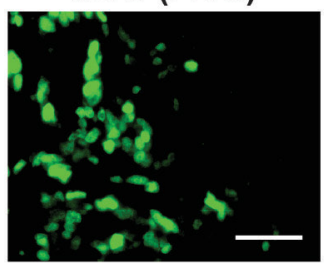

Overlay

Nuclei

B
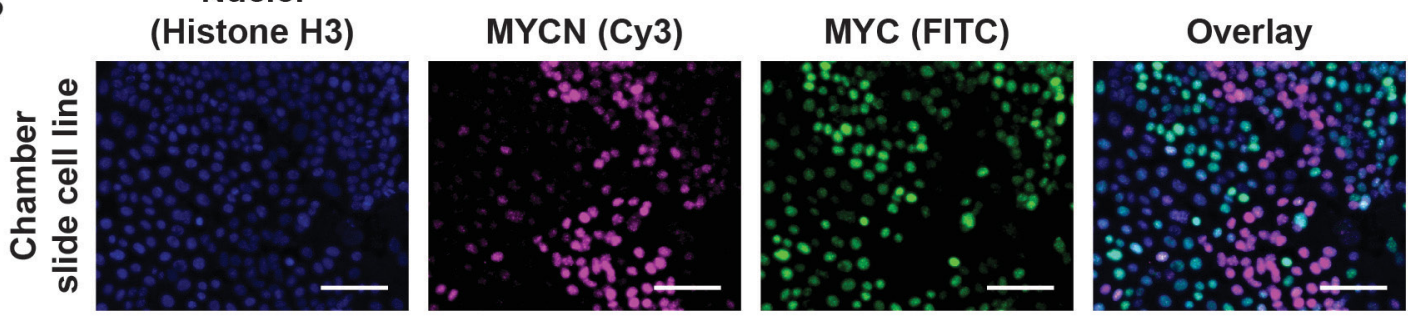

Figure 1. TSA-IF of MYCN and MYC in human tissue specimens and cell line cultures. A-

B. Representative TSA-IF stains of MYCN and MYC in an TNBC FFPE clinical specimen (A) and TNBC cell line grown in 8-well chamber slides for five days (B). Colors represent cell nuclei (blue), MYCN (magenta), and MYC (green). Scale bars $=20 \mu \mathrm{m}$.

\section{$\underline{\text { Notes }}$}

1. Do not allow the tissue to dry out.

2. Protect fluorophores from light exposure by covering the microscope slide moisture chamber during incubations and after tissue sections or chamber slides have been cover slipped.

3. All washes and blocking steps are conducted at RT.

4. Always include verified positive and negative controls for MYCN and MYC. Design the experiment so each control tissue is subjected to the entire protocol as well as individual primary stains. While antibody cross reactivity has not been observed between MYCN and MYC using this protocol, we suggest the investigator includes controls to confirm the absence of cross reactivity.

5. Incubations times with FITC and Cy3 SAB may need to be optimized for a given experiment.

6. Single or dual MYC family isoform TSA-IF can be multiplexed with other antibodies by performing additional rounds of antigen retrieval to strip previously conjugated antibodies. After which, a third TSA-IF reaction can be performed with Cy5 TSA reagent (PerkinElmer, catalog number: NEL745B001KT), or non-specialized IF protocols can be applied with secondary antibodies of any species.

\section{Recipes}

1. Permeabilization buffer $(0.1 \%$ Tween-20)

$1 \mathrm{ml}$ Tween-20 
$999 \mathrm{ml} 1 \mathrm{x}$ PBS

2. Blocking buffer ( $0.3 \%$ Triton $X-100,5 \%$ goal serum, $1 \times$ PBS)

$3 \mathrm{ml}$ Triton X-100

$50 \mathrm{ml}$ goat serum

$947 \mathrm{ml} 1 \mathrm{x}$ PBS

3. Antibody diluent ( $5 \%$ goat serum, $1 \times$ PBS)

$25 \mathrm{ml}$ goat serum

$475 \mathrm{ml} 1 \mathrm{x}$ PBS

4. Wash buffer $(0.1 \%$ Triton $X-100,0.25 \%$ goat serum, $1 \times$ PBS)

$1 \mathrm{ml}$ Triton X-100

$2.5 \mathrm{ml}$ goat serum

$996.5 \mathrm{ml}$ 1x PBS

5. FITC signal amplification buffer (SAB)

a. Reconstitute hydrolyzed FITC with $150 \mu \mathrm{DMSO}$

b. Immediate before each application of SAB, add $1 \mu \mathrm{l}$ of $30 \% \mathrm{H}_{2} \mathrm{O}_{2}$ to $200 \mu \mathrm{l}$ of $1 \mathrm{x}$ Plus Amplification Diluent $\left(\mathrm{H}_{2} \mathrm{O}_{2}\right.$ Additive)

C. To create the working $S A B$, calculate the volume needed for a given experiment and add FITC at 1:50 and $\mathrm{H}_{2} \mathrm{O}_{2}$ Additive at 1:100. For example, for $1 \mathrm{ml}$ of SAB, add $20 \mu \mathrm{l}$ of FITC and $10 \mu \mathrm{l}$ of $\mathrm{H}_{2} \mathrm{O}_{2}$ Additive to $970 \mu$ of $1 x$ Plus Amplification Diluent

Note: Prepare the FITC SAB immediately before use.

6. Cy3 signal amplification buffer (SAB)

a. Reconstitute hydrolyzed Cy3 with $150 \mu \mathrm{DMSO}$

b. Immediate before each application of $\mathrm{SAB}$, add $1 \mu \mathrm{l}$ of $30 \% \mathrm{H}_{2} \mathrm{O}_{2}$ to $200 \mu \mathrm{l}$ of $1 \mathrm{x}$ Plus Amplification Diluent $\left(\mathrm{H}_{2} \mathrm{O}_{2}\right.$ Additive)

C. To create the working $S A B$, calculate the volume needed for a given experiment and add Cy3 at 1:50 and $\mathrm{H}_{2} \mathrm{O}_{2}$ Additive at 1:100. For example, for $1 \mathrm{ml}$ of $\mathrm{SAB}$, add $20 \mu \mathrm{l}$ of $\mathrm{Cy} 3$ and $10 \mu \mathrm{l}$ of $\mathrm{H}_{2} \mathrm{O}_{2}$ Additive to $970 \mu \mathrm{l}$ of $1 x$ Plus Amplification Diluent

Note: Prepare the Cy3 SAB immediately before use.

\section{Acknowledgments}

We thank the patients who contributed tissue used in this study. This research was supported by: a grant from Incyte Corporation as part of the Incyte-Vanderbilt Alliance; an NCI grant CA068485; and a Susan G. Komen grant SAC110030. We thank the Translational Pathology Shared Resources Core, supported by the Vanderbilt-Ingram Cancer Center (P30 CA068485), and the Pathology and Tissue Informatics Core of the Specialized Program of Research Excellence (SPORE) in Breast Cancer (P50 CA098131) for their histopathological assistance and expertise. 


\section{Competing interests}

Funding for this research was in part provided by a research grant through Incyte Corporation. In reference to our corresponding manuscript, M.C.S. is a current employee of Incyte Corporation. P.C.C.L. and P.S. are former employees of Incyte Corporation; current affiliations are Kymera Therapeutics and Prelude Therapeutics, respectively.

\section{Ethics}

Tissue specimens used for development of the FFPE TSA-IF staining procedure were originally collected by clinical providers at the Vanderbilt-Ingram Cancer Center (VICC) and processed at the Vanderbilt University Medical Center (VUMC) Translational Pathology Shared Resources Core. Specimens were de-identified and data prohibited from release by established regulations and policies by the VUMC Institutional Review Board. VICC is an NCl-designated Comprehensive Cancer Center supported by P50 CA098131 that uses best practices for management of core services in accordance with $\mathrm{NCl}$ policy.

\section{$\underline{\text { References }}$}

1. Baratta, M. G., Schinzel, A. C., Zwang, Y., Bandopadhayay, P., Bowman-Colin, C., Kutt, J., Curtis, J., Piao, H., Wong, L. C., Kung, A. L., Beroukhim, R., Bradner, J. E., Drapkin, R., Hahn, W. C., Liu, J. F. and Livingston, D. M. (2015). An in-tumor genetic screen reveals that the BET bromodomain protein, BRD4, is a potential therapeutic target in ovarian carcinoma. Proc Natl Acad Sci U S A 112(1): 232-237.

2. Beltran, H. (2014). The N-myc oncogene: maximizing its targets, regulation, and therapeutic potential. Mol Cancer Res 12(6): 815-822.

3. Funa, K., Steinholtz, L., Nou, E. and Bergh, J. (1987). Increased expression of N-myc in human small cell lung cancer biopsies predicts lack of response to chemotherapy and poor prognosis. Am J Clin Pathol 88(2): 216-220.

4. Hurlin, P. J. (2013). Control of vertebrate development by MYC. Cold Spring Harb Perspect Med 3(9): a014332.

5. Kawagoe, H., Kandilci, A., Kranenburg, T. A. and Grosveld, G. C. (2007). Overexpression of NMyc rapidly causes acute myeloid leukemia in mice. Cancer Res 67(22): 10677-10685.

6. Lawson, D. A., Bhakta, N. R., Kessenbrock, K., Prummel, K. D., Yu, Y., Takai, K., Zhou, A., Eyob, H., Balakrishnan, S., Wang, C. Y., Yaswen, P., Goga, A. and Werb, Z. (2015). Single-cell analysis reveals a stem-cell program in human metastatic breast cancer cells. Nature 526(7571): 131-135. 
7. Malynn, B. A., de Alboran, I. M., O'Hagan, R. C., Bronson, R., Davidson, L., DePinho, R. A. and Alt, F. W. (2000). N-myc can functionally replace c-myc in murine development, cellular growth, and differentiation. Genes Dev 14(11): 1390-1399.

8. Schafer, J. S., Lehmann, B. D., Gonzalez-Ericsson, P. I., Marshall, C. B., Beeler, J. S., Redman, L. N., Jin, H., Sanchez, V., Stubbs, M. C., Scherle, P., Johnson, K. N., Sheng, Q., Roland, J. T., Bauer, J. A., Shyr, Y., Chakravarthy, B., Mobley, B. C., Hiebert, S. W., Balko, J. M., Sanders, M. E., Liu, P. C. C., Pietenpol, J. A. (2020). Targeting MYCN-expressing triple-negative breast cancer with BET and MEK inhibitors. Sci Transl Med 12(534). 